\title{
Fast geophysical prospection to map the archaeological site of Cocciano: preliminary results
}

\author{
VINCENZO SAPIA* ${ }^{*}$ FEDERICO FLORINDO**, \\ MARCO MARCHETTI *, MARIA DI NEZZA * \\ *Istituto Nazionale di Geofisica e Vulcanologia, Roma, Italy \\ ${ }^{* *}$ Gruppo Archeologico Latino "Latium Vetus", Monte Porzio Catone, Roma, Italy \\ vincenzo.sapia@ingv.it
}

\begin{abstract}
We present preliminary results of a multidisciplinary geophysical investigation applied to the subsoil imaging of the archaeological site of Cocciano, near Rome. We acquired capacitive coupled resistivity data along two parallel profiles and we performed a magnetic survey over a small subset of the survey area. The recovered resistivity models suggest the presence of a shallow, sub-horizontal, resistive layer ( $\rho>350$ $\Omega m)$, of slightly variable thickness $(2-3 \mathrm{~m})$, which we interpret as the response of ancient substructions overlying a relatively low-resistive layer, which we ascribe to the geological substratum. Processed magnetic data show a clear magnetic signature aligned to form a curve-shaped anomaly right at the prosecution of a nearby, partially exposed, ancient wall.
\end{abstract}

\section{INTRODUCTION}

The study area (Latitude N41 $49^{\prime} 11^{\prime \prime}$, Longitude E12 $\left.41^{\prime} 02^{\prime \prime}\right)$ is located in Cocciano, hamlet of the town of Frascati, inside the Colli Albani Volcanic District about 20 kilometers southeast of Rome. The investigation area regards the north-west-facing terrace in the property called Spinetta, which is most notably characterized by the presence of a sequence of substructional spaces opening on its front. The whole Spinetta area was place of a series of archaeological findings, which are generally recognized as the remains of a vast Roman villa of the imperial age, notably attributed to Emperor Tiberius (Valenti 2003a). As already reported from Valenti (2003b), some relevant archaeological features characterize the site:
- Lower substructions which constitute the north-western front of the Spinetta terrace, composed of a sequence of 36 vaulted rectangular spaces (Figure 1);

- Upper substructions which consist of further substructural spaces with vaulted ceilings located at the base of a late medieval (?) towerhouse;

- Caementicium wall, about $0.6 \mathrm{~m}$ thick, only partially emerging from the soil and vegetation and clearly showing a curved trend

(Figure 2).

With the aim to discover new buried archaeological features, non-invasive, fast and easydeployable geophysical measurements were performed using the magnetic and the capacitive coupled resistivity (hereinafter CR) methods (see Figure 3 for surveys location). 
Archaeological-related magnetic surveys are frequently reported in the literature of the past 50 years (Weaver, 1961; Bevan, 1994; Schmidt, 2007; Di Mauro et al., 2014). Conversely, CR measurements applied for similar studies, are far less used and only few scientific articles are available in the recent literature (Bottacchi et al., 2009; Alfouzan et al., 2016)

Two CR profiles were acquired over the Spinetta terrace, while the magnetic survey was conducted in an area where, an ancient wall, interrupt its circular trend and still, presumably, below the ground surface.

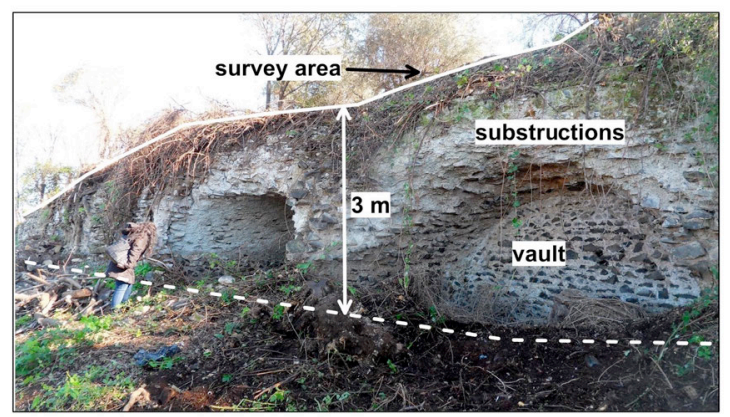

Figure 1. Example of the substructions located at the northwestern side of the survey area and forming the front part of the Spinetta terrace.

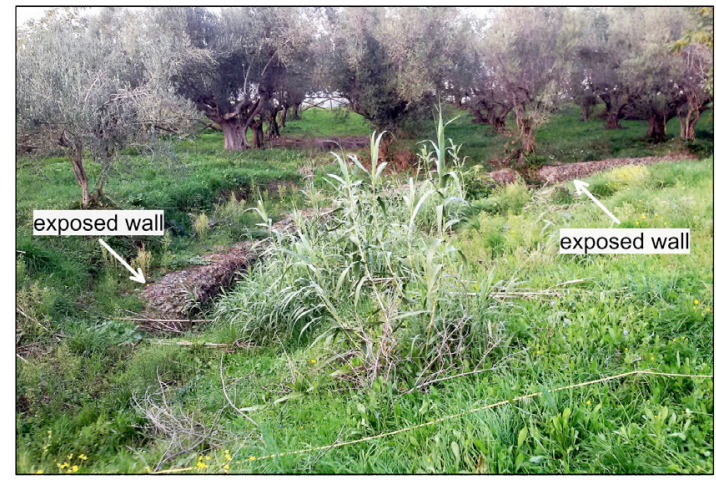

Figure 2. Ancient wall with a clear curved trend and an average thickness of about $0.6 \mathrm{~m}$ thick, only partially emerging from the soil and the vegetation.

Preliminary geophysical results are encouraging. We observe a high resistivity anomaly, of nearly constant thickness, throughout the ac- quired electrical data, which overlay a subhorizontal (3 $\mathrm{m}$ thick) relatively conductive layer. The extension of the surficial resistive layer is comparable to the observed substructions forming the front side of the Spinetta terrace as shown in Figure 2. The conductive layer is interpreted as fallout pericalderic scoriacone deposits of the final stages of the Villa Senni eruption cycle (Madonna degli Angeli succession, from $365 \pm 4$ to $351 \pm 4 \mathrm{ka}$ ) which crop out in the investigated area (Giordano et al., 2006; Marra et al., 2009). These deposits, especially along the Alban Hills caldera walls are made by alternating lava, scoria and welded scoria fall deposits. As for the magnetic data, the vertical gradient magnetic map highlights the presence of a clear curve-shaped magnetic anomaly resembling the trace, at depth, of the exposed wall structure trend.

\section{MEtHODS}

A scalar magnetometer G-858 by Geometrics (sensitivity $0.05 \mathrm{nT}$ ) in gradiometer configuration was employed with sensor separation of $0.8 \mathrm{~m}$ and lower sensor placed at about $0.3 \mathrm{~m}$ above the ground. Data were acquired in bidirectional mode along parallel paths about 2 $\mathrm{m}$ spaced, using a sampling rate of $1 \mathrm{~Hz}$. Acquired magnetic data were geo-referenced by means of an integrated GPS receiver (UTM projection, WGS84 coordinate system). The vertical magnetic gradient is computed by subtracting the measured bottom sensor magnetic data to the top sensor response. Since magnetic investigations depend on the contrast in the magnetic properties between the target and the enclosing soil matrix, a rapid magnetic susceptibility survey was performed. We used portable magnetic susceptibility meter (sensitivity 1 $\times 10^{-3}$ SI units) to complement the magnetometer survey and help with the interpretation of the recovered magnetic anomalies. Ground resistivity data were measured using a Geometrics OhmMapper system, using a multireceivers array and $5 \mathrm{~m}$ transmitter and receiver dipole. To increase subsoil investigation 
depth the two CR profiles, approximately west-east oriented, $15 \mathrm{~m}$ spaced apart and 150 $\mathrm{m}$ long, were collected using three different rope lengths of $5 \mathrm{~m}, 10 \mathrm{~m}$ and $15 \mathrm{~m}$ respectively. Raw data are corrected using the effective dipole lengths for line antennas (Oldenborger et al., 2013). Despiked and corrected apparent resistivity data are inverted with res2Dinv software using a smooth constrained leastsquared inversion algorithm (Loke and Barker, 1996).

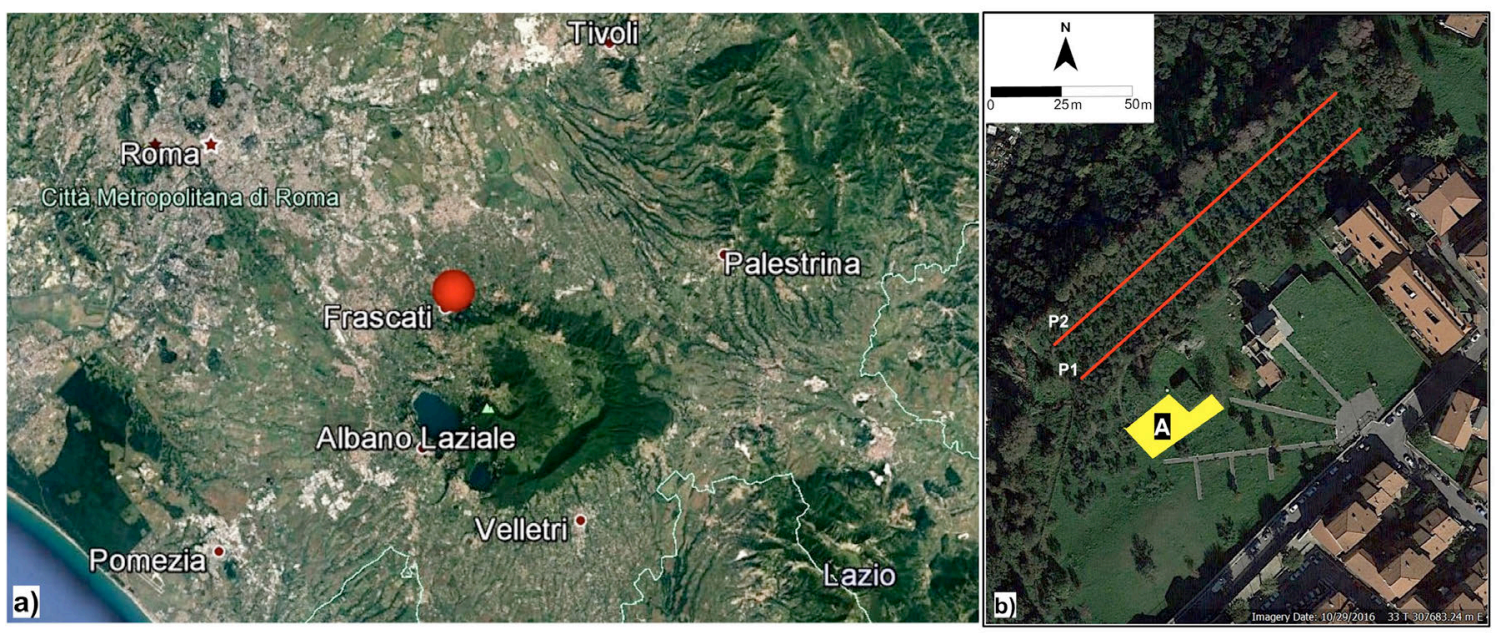

Figure 3. a) Location map of the area. The red dots indicate the survey area near the village of Frascati, Rome, Italy. b) Close up view of the survey area with the location of the geophysical measurements. The red lines show the CR profiles and the yellow box indicate the magnetic survey area.

\section{RESULTS}

The magnetic survey provided us valuable indications to speculate on the presence of a subsurface trace of the wall structure as the subsurface prosecution of the exposed wall. Data processing consisted of the removal of data spikes and other errors introduced during the survey, such as striping effect between lines. Among high intense, sparse and small-scale magnetic anomalies, the presence of a distinct magnetic signature in the vertical gradient magnetic map is evident. As shown in Figure 4 , this vertical magnetic gradient anomaly reaches an intensity of $-200 \mathrm{nT} / \mathrm{m}$ and is arranged to form an approximatively east-west oriented curve pattern. Due to its lateral continuity, this magnetic anomaly is probably relat- ed to the presence of a continuous magnetic sources, with less magnetic susceptibility than the surroundings, buried at very shallow depth. In fact, magnetic susceptibility measurements were carried out to characterize the magnetic properties of the exposed wall and the ground. Data were collected along the exposed wall and to the adjacent soil with a $2 \mathrm{~m}$ mark spacing. Measured data revealed that the ancient wall exhibits magnetic susceptibility values ranging from $12-17 \times 10^{-3}$ SI while the surrounding ground ranges from $5-9 \times 10^{-3} \mathrm{SI}$ units. Although very small, the difference between these values evidences a magnetic susceptibility contrast between the exposed wall and the soil.

Inversion results for the despiked $C R$ data along each profile are shown in Figure 5. 


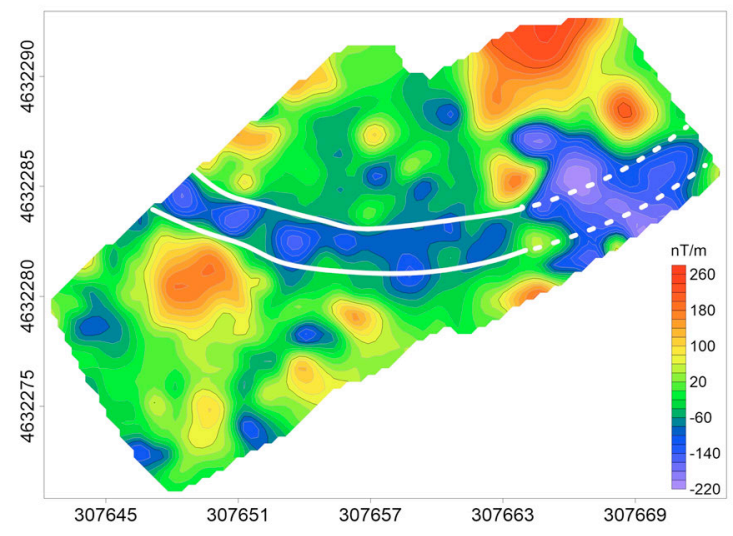

Figure 4. 2-D contour map of the magnetic vertical gradient. Data are pre-processed using the MagMap2000 software and then interpolated by the Kriging method using a regular grid of $3 \times 3 \mathrm{~m}$ cells.

In general, the recovered resistivity models clearly show two distinct electrical units. From the surface down to about $3 \mathrm{~m}$ depth, we observe a relative higher resistivity response of the subsurface materials. In particular, profile P1 (Figure 5a) shows a resistive layer of slightly variable thickness with resistivity values above $400 \Omega \mathrm{m}$ throughout its entire length. This layer overlays a sub-horizontal, $3 \mathrm{~m}$ thick low-resistive layer with minimum resistivity values of about $60 \Omega \mathrm{m}$. Below this layer, the P1 $\mathrm{CR}$ resistivity model hints to a high resistive layer at depth. Similar results come up also from the CR profile P2 (Figure 5b). The shallower portion of the subsoil clearly shows a high resistive layer, about $3 \mathrm{~m}$ thick, which overlays a sub-horizontal $3 \mathrm{~m}$ thick lowresistive layer up to a depth of $7 \mathrm{~m}$. Again, the recovered $C R$ model indicates that the resistivity increases at depth, although we are aware that the resistivity features at the bottom of each $C R$ profiles are in a lower sensitivity region and they could reasonably be explained as numerical artifact of the inversion.

\section{DisCUSSION}

This short paper presents the preliminary results of a geophysical survey conducted in the Cocciano-Spinetta archaeological site. The aim of this work was to check the feasibility of two fast and easy-deployable geophysical methods as a tool for detecting the presence of subsurface archaeological targets. The success of any magnetic investigation strictly depends on the existing magnetic contrast between the feature of interest and the soil. In this case, the ancient wall is made of leucitite shards, an effusive volcanic rock type, mixed to a fine concrete matrix. The magnetic susceptibility contrast between the volcanic rock and the surrounding soil supports the recorded magnetic data and facilitates the interpretation of the observed magnetic anomalies.

The magnetic results allowed us to confirm a circular trend of the wall, in accordance to what proposed by Valenti (2003a). The recovered negative vertical magnetic gradient anomaly, right at the prosecution of the wall, can be due to: a) the magnetic properties of the wall are different at depth, $b$ ) the wall has been entirely replaced with materials characterized by different magnetic properties. The first option will involve the partial substitution of the wall with soil of significantly lower magnetization. The second option implies that the wall has been entirely removed from its original position and replaced with less magnetic susceptibility soils. Both options would justify the link between the recovered negative vertical magnetic gradient anomaly and the lack of the wall (which showed higher magnetic susceptibility), thus ascribing the recovered magnetic gradient response to the presence of its trace at depth. 


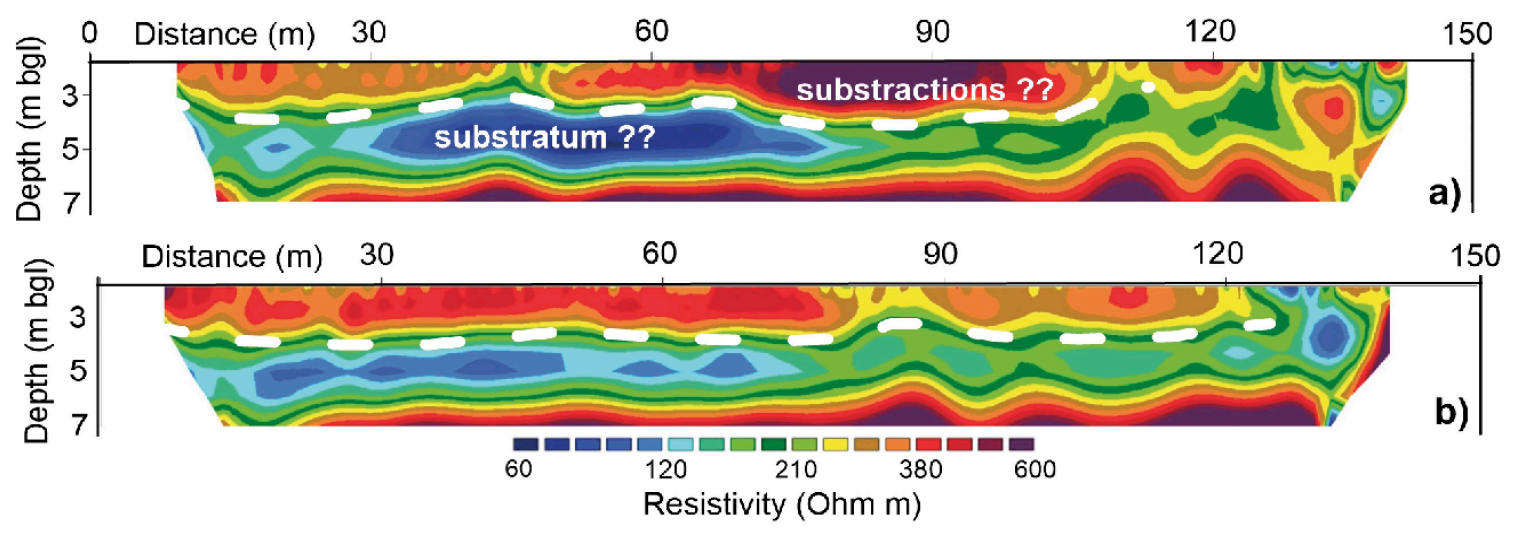

Figure 5. CR subsurface resistivity inversion models for the a) P1 profile with RMS $=0.8 \%$ (with left being south-west and right north-east), b) P2 profile with RMS $=1.1 \%$ (with left being south-west and right northeast), Same resistivity colour scale is adopted for the two CR profiles. Dashed white line hypothesizes the substructions / bedrock boundary.

We considered the CR survey as a very useful tool for a preliminary investigation of the subsoil prior to set up a more laborious electrical resistivity tomography measurements (Sapia et al., 2017). In fact, the OhmMapper instrument was found to be very fast and accurate to map the subsurface resistivity up to about $7 \mathrm{~m}$ depth. We were able to acquire two parallel electrical profiles, each $150 \mathrm{~m}$ long, using three rope lengths for a total path of almost $800 \mathrm{~m}$ in less than one hour (see HRA-P1 and HRA-P2 in Figure 6). The overall resistivity distribution evidenced the presence of a high resistive layer up to a depth of $3 \mathrm{~m}$, which is coincident with the thickness of the north-western substructions (see Figure 1). In our opinion, the high resistivity could be the response of such a mixture of bricks and concrete as observed from the exposed substructions which is in contrast with the hypothesis of decorative front wall as reported from Valenti (2003a, b).

The Spinetta terrace, although taking advantage of the natural slope of the hill, is clearly artificial. Facing north-west it overlooks a very impressive landscape (today partly covered by constructions and the Rome-Frascati railway artificial slope) ranging from Rome to the
Monti Tiburtini, visually dominating the whole eastern "Ager Romanus".

This preliminary study indicates that both magnetic and CR techniques can be used for archaeological investigation purposes in Cocciano. In the near future the geophysical survey will be extended to other sectors of the archaeological area. In particular, electrical resistivity tomography (ERT) will be acquired either over the terrace or to image the subsoil below the circular wall structure. The ERT data collected over the same profile as the CR can be also used to cross-check both recovered resistivity models. In addition, new CR profiles will be performed parallel to HRA-P1 and P2 sections in order to cover the entire terrace area. By this way, CR and ERT data could then be used to build up a 3D resistivity model of the whole Spinetta terrace up to a depth of about $20 \mathrm{~m}$. A combined use of magnetic and ground penetrating data (GPR) will be planned over two, infrastructure-free, subset areas located both at the eastern and western side of the archaeological site with the aim to image the presence of further buried targets (i.e. buried walls, floorings, roads). 


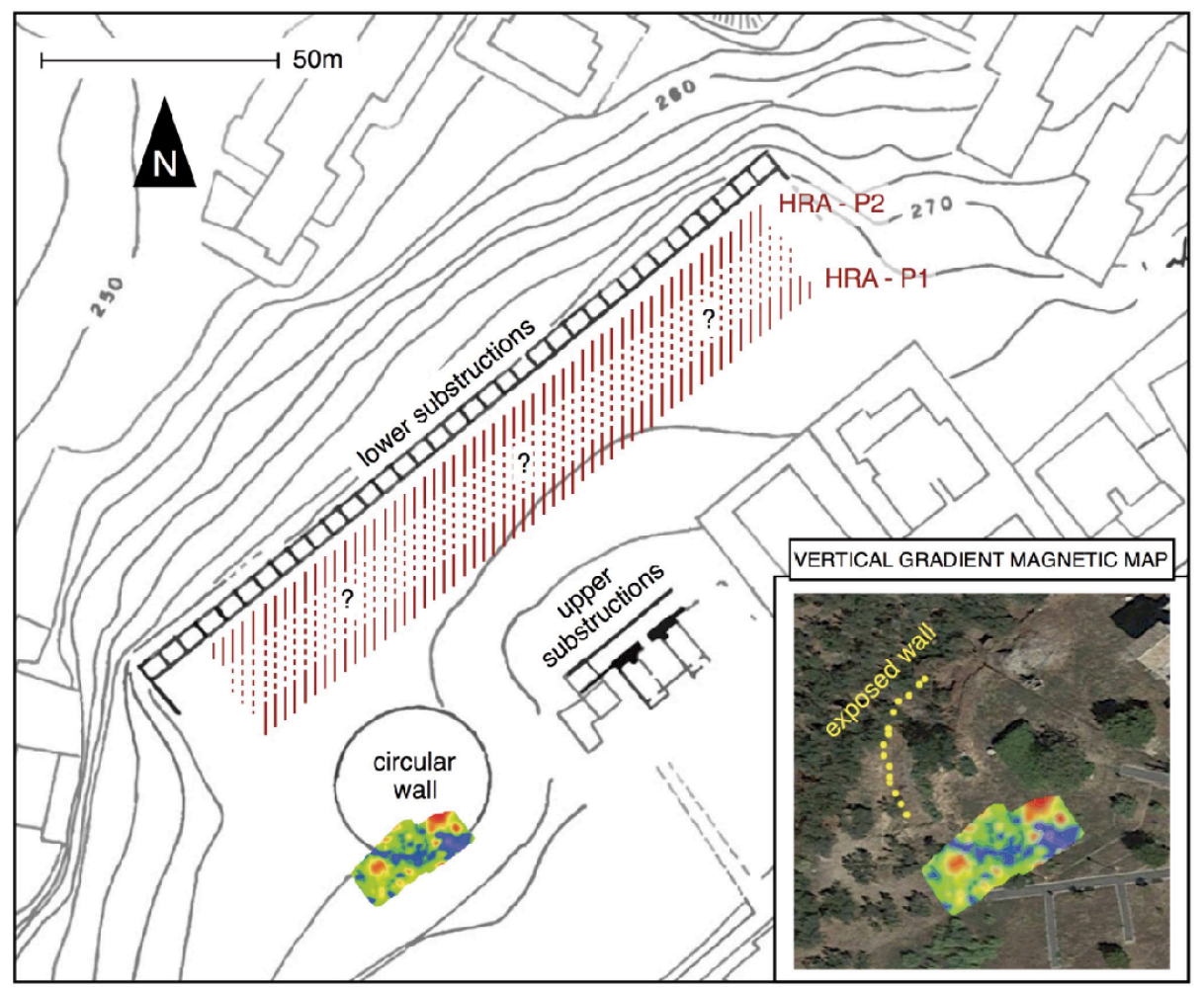

Figure 6. General planimetry of the study area adapted from Valenti (2003a) showing the substructional structures, with schematization of the High Resistivity Areas (HRA) resulted from the two CR profiles (P1 and P2) and results from the magnetic survey carried out in the area of the caementicium circular wall.

\section{ACKNOWLEDGEMENTS}

The authors kindly thanks Enrico Devoti and Giovanna Cappelli for their valuable assistance during the fieldwork. We also thanks the reviewer for the constructive comments and helpful suggestions which helped us to improve the manuscript.

\section{REFERENCES}

Alfouzan, F., Zhou, B., Bakkour, K., and Alyousif, M. (2016). Detecting near-surface buried targets by a geophysical cluster of electromagnetic, magnetic and resistivity scanners. Journal of Applied Geophysics, 134:55-63.
Bevan, B. W. (1994). The Magnetic Anomaly of a Brick Foundation. Archaeological Prospection, 1, 93.

Bottacchi, M. C., Colonna, T., Mantovani, F., and Medri, M. (2009). Application of the OhmMapper resistivity-meter to detect the theatre of Sentinum Roman town by using 3D resistivity model. ArcheoSciences. Revue d'archéométrie, 267-269.

Di Mauro, D., Alfonsi, L., Sapia, V., and Urbini, S. (2014). A neighborhood revealed by geophysical prospection: An example of urbanization at the Phoenician-Punic settlement of Mozia (western Sicily, Italy). Journal of Applied Geophysics, 104:114-120.

Giordano, G., De Benedetti, A. A., Diana, A., Diano, G., Gaudioso, F., Marasco, F., Miceli, 
M., Mollo, S., Cas, R. A. F., and Funiciello, R. (2006). The Colli Albani mafic caldera (Roma, Italy): stratigraphy, structure and petrology. Journal of Volcanology and Geothermal Research 155:49-80.

doi:10.1016/j.jvolgeores.2006.02.009.

Loke, M. H., and Barker, R. (1996). Rapid leastsquares inversion of apparent resistivity pseudo-sections using a quasi-Newton method. Geophys. Prospect. 44:131-152.

Marra, F., Karner, D. B., Freda, C., Gaeta, M., and Renne, P. (2009). Large mafic eruptions at Alban Hills Volcanic District (Central Italy): Chronostratigraphy, petrography and eruptive behavior, Journal of Volcanology and Geothermal Research 179:217-232. doi:10.1016/j.jvolgeores.2008.11.009.

Oldenborger, G. A., and LeBlanc, A. M. (2013). Capacitive resistivity inversion using effec- tive dipole lengths for line antennas. Journal of Applied Geophysics, 98:229-236.

Sapia, V., Baccheschi, P., Villani, F., and Marchetti, M. (2016). Multidisciplinary geophysical approach to map disposal site: the Ponza island case study. Journal of Applied Geophysics, 138:264-274.

Schmidt, A. (2007). Archeology, magnetic methods. In Encyclopedia of Geomagnetism and Paleomagnetism, Springer Netherlands 23-31.

Valenti, M. (2003a). Ager Tusculanus, Leo S. Olschki Editore, Firenze., Forma Italiae Serie I, 41:428 pp.

Valenti, M. (2003b). Gli scavi nella Vigna Lucidi a Frascati, in Ghini G., Lazio Sabina 2, De Luca Editori d'Arte, Roma, 187-192.

Weaver, G. H. (1961). Magnetic dating measurements. Archaeometry, 4:23-28. 